УДК 811.11

DOI: 10.6060/BHIISUCT2020_228

\title{
Крупина Е.А.
}

Крупина Екатерина Алексеевна - кандидат филологических наук,

ФГБОУ ВО «Ивановский государственный университет», доцент кафедры английского языка факультета. E-mail: ryabtseva.e.a@ yandex.ru

\section{ГЛОССАРИИ К ДРЕВНЕАНГЛИЙСКОЙ ПОЭМЕ «БЕОВУЛЬФ» КАК СРЕДСТВО ПОЗНАНИЯ КУЛЬТУРЫ АНГЛОСАКСОВ}

В работе представлены результаты анализа глоссариев к древнеанглийской поэме «Беовульф» Б. Торпа (1855), Э. Уайета (1894), У. Дж. Сэджфилда (1910), Р. Чемберса (1914), Ф. Клэбера (1922). Целью работы является рассмотрение макроструктуры представленных выме глоссариев. На основе лексикографического анализа были выявлены основные принципы описания имен собственных в данных справочниках. На основе статистического анализа были выявлены основные значимые элементы культуры англосаксов на примере наименований человека, а именно война, семья и родственные узы, социальные связи, тема пира, путешествия.

Ключевые слова: Беовульф, глоссарий, культура, англосаксы, древнеанглийский эпос, наименования человека.

\section{Krupina E.A.}

Krupina E. A. - Candidate of Philology, Associate Professor, Ivanovo State University. E-mail: ryabtseva.e.a@yandex.ru

\section{OLD ENGLISH POEM "BEOWULF" GLOSSARIES AS A MEANS OF PERCEPTION OF ANGLO-SAXON CULTURE}

The article presents the results of the analysis of the glossaries to the Old English poem "Beowulf". They are glossaries by B. Thorpe (1855), A. Wyatt (1894), J. Sedgefield (1910). R. Chambers (1914), F. Klaeber (1922). The purpose of the work is to observe the macrostructure of the dictionaries given above. The lexicographic analysis showed the main principles of proper names presentation in the given dictionaries. The main meaningful elements of Anglo-saxon culture on the basis of the names of a person were defined with the help of the statistical analysis. They are the theme of war, family and relatives, social ties, feast and travelling.

Key words: Beowulf, a glossary, culture, Anglo-Saxons, Old English literature, denomination of a man.

«Беовульф»- это единственное крупное произведение древнеанглийской поэзии, текст которого полностью сохранился до наших дней. В поэме прослеживается начинавшийся в тот период процесс зарождения феодальных связей. Произведению, 
однако, присуща эпическая архаизация. Кроме того, она представляет действительность со специфической точки зрения: мир «Беовульфа» - это мир королей и дружинников, мир пиров, битв и поединков. Несомненно, что аудиторией для прослушивания поэмы «Беовульф» была аристократия. Именно на эту социальную группу было ориентировано произведение. Поэт описывает церемонию при дворе, манеры, поведение людей, а также драгоценные изделия, которые раздаются как дары. Таким образом, поэт представляет слушателю или читателю языческий мир со всеми его церемониями дарения и награждения.

Функцией героической литературы или героической пьесы было восхваление, а таким образом, и увековечивание героического поведения. В песнях такие герои, как Беовульф, сами рассказывали о своих путешествиях, а поэты веселили героев на пиршествах рассказами о прошлых подвигах; германские герои на «медовых скамьях» гордились прошлым и обещали победы в будущем. Величие и честь воплощались в подаренных кольцах, меде и оружии; позор и трусость приводили к поражению и изгнанию или рабству, которым предпочиталась смерть. Этот код поведения был социальным институтом, реальностью. [7, с. 56]

Древнеанглийская поэма «Беовульф» - это поэма о блистательных возможностях общества - красота драгоценных камней, многочисленные песни в зале, праздничное настроение, но она также о границах человеческих возможностей, эти границы очерчиваются поражениями конкретных людей. В то время люди жили по определенным правилам: конунги вели войны, правили и умирали; королевы выходили замуж, производили на свет наследников и боролись за поддержание мира. Молодые воины совершали подвиги в надежде на великие награды, в пиршественном зале все веселились, слушали песни о великих героях. Но некоторые конунги проигрывали войны, а молодые воины не совершали подвигов. Когда встает вопрос выбора между благом для всего общества и благом для отдельных личностей, когда личные желания расходятся с социальными убеждениями, идеальный мир пиршественного зала рушится $[6$, с. 580$]$.

Тенденция к идеализации повлияла на поэтический словарь, в большей степени на типичные выражения, чем на индивидуальный стиль. В героических песнях и хвалебных речах, которые должны были слагать германские придворные поэты, ситуации были стереотипными; темы обычно иллюстрировали идеальные отношения между воином и хозяином или конфликт долга и интересов, с которым может столкнуться воин. Разрешения конфликтов также были традиционны. Поэзия восхваляла кодекс чести воина и отражала идеалы поведения в германском обществе. В соответствии с вкладываемым смыслом поэт находил типовые выражения, причем прямо или с помощью коннотации, выделял те качества человека или вещи, которые казались более правильными, добрыми, приятными и характерными для того общества, в котором слагалось произведение. На обозначение также влияли метр и аллитерация, также они были толчком для создания новых обозначений людей и предметов [9, с. 1-28].

Древнеанглийская поэма «Беовульф» представляет интерес не только для ученых-литературоведов, но для ученых-филологов, лингвистов. Так, с точки зрения лексикографии, важным аспектом изучения данного произведения представляется исследование словарей к поэме. По классификации, представленной Крупиной Е. А., выделяется пять периодов составления различных типов словарей с различным мега-, макро- и микроструктурным наполнением. В начале XIX - середине XIX века была предпринята первая попытка составления глоссария к древнеанглийской поэме «Беовульф». Дж. Кэмбэл разработал первый подобный справочник в 1833 году после того, как поэма была найдена. В середине XIX веке выходит прикнижный глоссарий Б. Торпа (1855 год). Он отличается увеличением объема входных единиц, кроме того состави- 
тель приводит грамматические и этимологические пометы, однако не всегда последовательно. В конце XIX - начале XX века появляются глоссарии увеличенного объема, также они содержат лингвистическую информацию. Начало XX века знаменуется появлением первого конкорданса к древнеанглийской поэме «Беовульф», который был составлен А. Куком в 1911 году. Середина XX века отмечена увеличением работы над конкордансами, особенно с появлением компьютеров. Конкорданс к древнеанглийской поэме «Беовульф» Дж. Бессинджера 1968 года может служить ярким примером подобного словаря. Вторая половина XX века и начало XXI века отмечены попытками представить наиболее компактно не только лингвистическую информацию о поэме, но и отобразить эпоху, когда была составлена и записана поэма, eе культуру [2, с. 161-162].

В последнее время словари в широком понимании начинают рассматриваться как словари, отражающие культуру той страны, где они были созданы. В словарях запечатлены не только языковые явления. Сегодня справочники содержат описание культурных явлений, тем самым формируют мировоззрение носителей языка. Все изменения, происходящие в обществе, его ценности, верования увековечиваются в словарях [8, с. 202]. Более того, некоторые словари сохранили память народа или нации, в них запечатлены явления, существовавшие в прошлом и не существующие в настоящем. С этой точки зрения, по мнению Г. Штейнера, словари являются своего рода атласом, путеводителем по культуре определенной нации [13, с. 97]. О.А. Ужова отмечает, что, с одной стороны, словарь - это продукт культуры, достижение науки на определенном этапе развития общества. Однако под определенным углом зрения уровень культуры определяется уровнем совершенствования лексикографической науки [5, с. 47]. Н. Б. Мечковская полагает, что денотативность лексики определяет культурную составляющую словарей [3, с. 58-59].Словарь, отражающий память народа, является средством познания мира, рожденного человеческим сознанием. Подобные словари в широком понимании могут быть названы словарями культуры [4].

Эпические произведения древнеанглийской поэзии отражают значимые пласты культуры древнеанглийского общества [1, с. 3]. Анализ входных единиц справочников к поэме может расширить понимание культуры англосаксов. С этой целью был проведен анализ следующих глоссариев к древнеанглийской поэме «Беовульф»: Б. Торпа (1855), Э. Уайета (1894), У.Дж. Сэджфилда (1910), Р. Чемберса (1914), Ф. Клэбера (1922).

На примере анализа имен существительных (простых наименований человека) можно выделить группы слов, входящих в глоссарий. В глоссарии Б. Торпа (1855) наиболее многочисленную группу слов представляют наименования родства: bearn, brōpor, byre, cnosl, dohtor, eafera, ēam, m̄̄g, fæder, mecg, mōdor, nefa, sunu, wīf; наименования правителя: æpele, baldor, brego, cwēn, cyning, fengel, frēa, hlāford, rǣswa, pengel, pēod. Часто встречаются наименования воина: beorn, eorl, hæleð, ōretta, rinc, secg; наименования, обозначающие профессии: ār, ombeht, smið, pegn, pyle; друзей и товарищей: gædeling, ge-selda, wine; наименования человека по полу: oniht, ides, wif, brȳd; по возрасту: geogoð. Выделяются слова - наименования человека как абстрактное понятие: ceorl, fyr, guma, man, nīp, wer, wine. А также встречается наименование человека, относящееся к теме пира: byrele.

В глоссарии Э. Уайета (1894) большая часть существительных представлена наименованиями видов деятельности, где, в свою очередь, основную массу представляют наименования человека, связанные с войной: rinc, weard, wiga, wīgend, ōretta, scota, freca. В глоссарии представлены около 10 простых наименований господина: bealdor, cyning, brego, dryhten, ealdor, hlāford, eorl, fengel, frēa. Также встречаются наименования врага: fēond, ge-winna, in-genga, sceawere; друга: frēond, wine, ge-bedda; наименования 
человека, связанные с пиршественным залом: ge-selda; а также наименования человека вообще: man, mon, secg, guma, cearl. Немаловажную роль играют и наименования родства: brȳd, dohtor, eafora, ēamm, māge, mōdor, wif; профессий: smið. Необходимо отметить разделение понятий по возрасту и полу: iū-monna, ides, wif.

На примере анализа имен существительных можно выделить группы слов, входящих в глоссарий Уолтера Джона Сэджфилда (1910). Основную массу составляют имена существительные, относящиеся к военной тематике: rinc, beorn, cyning, wiga, cempa, garwiga, wīsa, hildefrece и др. Глоссарий содержит около 10 простых наименований воина (rinc, ōretta, rīdend, scēotend, wiga, freca, wīgend). Многочисленную группу слов представляют наименования человека как члена общества: ambiht, dryhten, bealdor, brego, cwēn, cyning, ealdor, eorl, fengel, wita и др. Исходя из анализа, можно выделить основные наиболее часто использующиеся наименования: наименования правителя, советников, воинов, приближенных ко двору, слуг. Немаловажную роль играют наименования родства: bearn, brȳd, brōðor, byre, dohtor, ēam, fæder, mǣg, magu, mōdor, sunu и др. Следующая группа - наименования к слову товарищ, друг: gestealla, wine, byrele, freond. Некоторые наименования указывают на еще одно важное для англосаксов место - пиршественный зал: byrele и др. Деление по типам занятости достаточно условно, в основном здесь мы находим наименования людей, занимающихся войной (воины, стрелки, всадники, стража), управлением, а также наименования слуг и служанок (mægð, fǣmne), приближенных правителя (ðеgn). Необходимо отметить, что в глоссарии есть наименование поэта (scop). Особое место занимают наименования врага, преступника: bana, feond, hettend, leassceawere, gesacu и др. Следует отметить, что в глоссарии выделяются слова, отражающие возраст и пол человека: cyning, cwēn, geogoð, geomann, hyse, fǣmne, bearn, dohtor, ēam, mage, sunu и др.

На примере анализа имен существительных (простых наименований человека) можно выделить группы слов, входящих в глоссарий Р. Чемберса (1914). Большую часть имен существительных составляют наименования родства (7 статей) и наименования воинов (5 статей), также есть наименования человека по роду занятий, по полу, человека как абстрактное понятие.

Большая часть существительных в глоссарии Ф. Клэбера (1922) представлена наименованиями видов деятельности, где, в свою очередь, основную массу представляют наименования человека, связанные с войной и наименования господина: liðend, rīdend, sceotend, scop, smið, pyle, weard, æpeling, bealdor, beorn, brego, cempa, ceorl, cyning, dēmend, dryhten, ealdor, eorl, frēa, hæle, ombeht, ōretta, rǣswa, scealc, strengel, pengel, pegn, peoden, wiga, wīgend, wita. Следующая группа наименований — наименования родства: bearn, brōðor, byre, dohtor, eafora, ēam, fǣder, gædeling, ge-brōðor, mǣg, maga, mage, mago, mōdor, nefa, sunu. Также встречаются наименования врага: bana, feond, hettend, sceapa, peaf; друга: freond, ge-bedda, ge-sīð, wine; наименования человека, связанные с пиршественным залом: byrele; а также наименования человека вообще: man, mon, secg.

На примере простых наименований человека были выявлены следующие группы слов, входящие в макроструктуру словарей. Основную массу составляют существительные, относящиеся к теме войны. Многочисленную группу слов представляют наименования человека как члена общества, например, dryhten (правитель), cwen (королева), cyning (конунг), eorl (эрл) и другие. Исходя из анализа, можно выделить основные наиболее часто использующиеся наименования: наименования правителя, советников, воинов, приближенных к двору, слуг. Немаловажную роль играют наименования родства, например, broðor (брат), dohtor (дочь), fæder (отец), modor (мать), sunu (сын) и др. Меньшую группу представляют наименования к слову товарищ, друг. Многие наименования указывают на еще одно важное для англосаксов место - пиршественный зал. 
Деление по типам занятости достаточно условно, в основном здесь мы находим наименования людей, занимающихся войной (воины, стрелки, всадники, стража), управлением, а также наименования слуг и служанок (mægð, fæmne), приближенных правителя (ealdorðegn). Необходимо отметить, что в некоторых глоссариях присутствует наименование поэта (scop). Особое место занимают наименования врага, преступника. Следует отметить, что в справочниках выделяются слова, отражающие возраст и пол человека: cyning, cwen, eam, mage, sunu и др.

Таким образом, наибольшее число лексем из простых наименований человека приходится на обозначение воинов и термины родства. Немного меньшую группу составляют лексические единицы, обозначающие тип деятельности человека. Реже встречаются обозначения человека как абстрактное понятие (человек вообще), разделение людей по полу и возрасту, понятия друг и враг, термины, относящиеся к путешествиям.

\section{ЛИТЕРАТУРА}

1. Гвоздецкая, Н. Ю. Язык и стиль древнеанглийской поэзии (Проблемы поэтической номинации) / Учебное пособие. Иваново, 1995. $151 \mathrm{c.}$

2. Крупина Е. А. Словари к древнеанглийской поэме «Беовульф», становление и современное состояние: дис. ... канд. филол. наук: 10.02.04. Иваново, 2018. 200 с.

3. Мечковская, Н. Б. Семиотика: Язык. Природа. Культура. М., 2008. 432 с.

4. Оссовецкий, И. А. Лексика современных русских народных говоров. М.: Наука, 1982. $195 \mathrm{c}$.

5. Ужова, О. А. Словарь в культуре, культура в словаре. Иваново: Иван. гос. хим.-тех. унT, 2011. $201 \mathrm{c}$.

6. A Companion to Medieval Poetry / Corinne Saunders. Blackwell Publishing Ltd., 2010. $821 \mathrm{pp}$.

7. Alexander M. Old English Literature / London, 2002. 299 pp.

8. Bejoint, H. The Lexicography of English. From Origins to Present. N.Y.: Oxford University Press, 2010. $544 \mathrm{pp}$.

9. Brodeur, A. G. The Art of Beowulf. Berkley, LosAngeles, 1959. PP. 108-112.

10. Glossary // Beowulf and the Fight at Finnsburgh. First edition. Boston, 1922.

11. Glossary // Beowulf. First edition. Manchester University Press, 1910.

12. Glossary // The Anglo-Saxon poems of Beowulf. The scop or gleeman`s tale. The Fight at Finnesburg. Oxford, 1855.

13. Steiner R.J. Rev. of the Oxford Spanish Dictionary: Spanish-English, English-Spanish. / R.J. Steiner. 2nd ed. // International Journal of Lexicography 10.3, 1986. pp. 171-216.

\section{REFERENCES (TRANSLITERATED)}

1. Gvozdetskaya N.Yu. Yazyk I stil drevneangliiskoi poezii (Problemy poeticheskoi nominatsii) / Uchebnoe posobie. Ivanovo, 1995. $151 \mathrm{~s}$.

2. Krupina E.A. Slovari k drevneangliickoi poeme "Beowulf", stanovlenie I sovremennoe sostoyanie: dis. ... kand. philol. nauk; 10.02.04. Ivanovo, 2018. $200 \mathrm{~s}$.

3. Mechkovskaya, N.B. Semiotika; Yazyk. Priroda. Kultura. M., 2008. 432 s.

4. Ossovetskii I.A. Lexika sovremennyh russkih narodnyh govorov. M.; Nauka, 1982. 195 s.

5. Uzhova O.A. Slovar` v culture, kul tura v slovare. - Ivanovo: Ivan. gos. khim-teh. un-t, 2011. $201 \mathrm{~s}$. .

6. A Companion to Medieval Poetry / Corinne Saunders. Blackwell Publishing Ltd., 2010. $821 \mathrm{pp}$.

7. Alexander M. Old English Literature / M. Alexander/ — London, 2002. — 299 pp.

8. Bejoint, H. The Lexicography of English. From Origins to Present / H. Bejoint. - N.Y.: Oxford University Press, 2010. — $544 \mathrm{pp}$.

9. Brodeur, A. G. The Art of Beowulf / A.G. Brodeur. Berkley, LosAngeles, 1959. PP. 108-112.

10. Glossary // Beowulf and the Fight at Finnsburgh / F. Klaeber. First edition. Boston, 1922.

11. Glossary // Beowulf / W.J. Sedgefield. First edition. Manchester University Press, 1910. 
12. Glossary // The Anglo-Saxon poems of Beowulf. The scop or gleeman`s tale. The Fight at Finnesburg / B. Thorpe. Oxford, 1855.

13. Steiner R.J. Rev. of the Oxford Spanish Dictionary: Spanish-English, English-Spanish. / R.J. Steiner. 2nd ed. // International Journal of Lexicography 10.3, 1986. pp. 171-216.

Поступила в редакцию 20.02.2020 г. Принята к публикации 03.03.2020 г.

Для ичитирования:

Крупина Е.А. Глоссарии к древнеанглийской поэме «беовульф» как средст-во познания культуры англосаксов // Вестник Гуманитарного института. 2020. № 1. С. 228-233. URL: https://isuct-bhi.ru/sites/default/files/issue/2020/1/bhi-2020-1-228.pdf 